\title{
FEM 2D Analysis of Mild Traumatic Brain Injury on a Child
}

\author{
Ernesto Ponce and Daniel Ponce \\ Escuela Universitaria de Ingeniería Mecánica, \\ Universidad de Tarapacá, Arica, Chile \\ eponce@uta.cl
}

\begin{abstract}
Traumatic brain injury is one of the most frequent causes of disability amongst children and adolescents. There are cognitive and neurological effects caused by repetitive head injuries. Learning deficiency is likely to be the result of early head injurie. This may impact the ability to control emotions and exhibit inappropriate behaviour. These children have trouble responding to subtle social cues and planning difficult tasks. Concussions can occur whenever there is a collision of the head against a hard object. The aim of this investigation is the modelling, by means of the two-dimensional Finite Element Method, of brain stress in children caused by head injuries. Three impact cases were analyzed: a concentrate left brain side blow, a diffused blow and a frontal head collision. The brain damage is determined by comparing the last resistance of the arteriole and neurone. The mathematical models can be used for protective design and demonstrating the brain damage.
\end{abstract}

Keywords: brain injury; computational neuroscience; bio-informatics; finite elements.

\section{Introduction}

A child's brain is extremely delicate as it is still developing and does not have the strength of an adult's. In young children the neck muscles are not fully developed, and therefore the head has little protection when exposed to sudden or violent swings. Moreover, as the skull is still developing, it provides little defence due to the low bone density. The head of a child is proportionately larger than his body, making accidents more likely to happen. The features of children's biological material are different to those of adults, as their tissues contain more water and are less resistant to stress. Children's skulls have a density of around 1,1 g/cm3, while adults reach $1,3 \mathrm{~g} / \mathrm{cm} 3$, therefore the former skull mechanical resistance is less. Within a juvenile's skull there is a very delicate electrochemical mechanical balance that is evolving as the brain and its sensitivity grow. Physical impacts are likely to damage the neurones as they cut into the myelin causing its internal sodium ions to slowly escape and to be replaced by calcium ones.

In flexible isotropic materials, the magnitude of fault tensions caused by rupture is half of those of longitudinal tensions, making the brain tissue particularly vulnerable. In the long term, these fault tensions will cause the neurones

A. Ghosh, R.K. De, and S.K. Pal (Eds.): PReMI 2007, LNCS 4815, pp. 186 191, 2007.

(C) Springer-Verlag Berlin Heidelberg 2007 
to die. One potential cause of mild traumatic brain injury is the heading of soccer balls, head injury in a bike crash and playing others sports. Additional damage can occur due to communication interruption between the frontal lobe, and the amygdala, which resides in the centre of the brain controlling emotions. This type of damage may in the long term bring about aggressive behaviour. Research shows that physically abused children may become antisocial adults, Raine, 7] and The Franklin Institute on Line, 9]. There is little analysis, by means of finite elements, in relation to brain damage caused by light impact. The mild traumatic brain injury on a child is described and classified by Lee, [2] and Münsterberg, [4. The images are based on the experience of Ourselin: [5], Pitiot: 6], The Virtual Human Brain [10] and Yong: [12.

\section{Theory}

The system of equations of finite elements shown below are of the elastic linear type, described by Zienkiewicz, [13]:

$$
K D=F
$$

Where:

$\mathrm{K}$ is the rigidity matrix.

$\mathrm{D}$ is the vector of nodal displacement.

$\mathrm{F}$ is the vector of applied loads.

In this work, four different materials have been used: Skin, skull bone, brain fluid and brain tissue. The first three materials are laid out in layers, the last one being the brain tissue. Every material has different properties and geometry. Each one will have a distinct matrix of rigidity. The equation (11) would therefore end up as:

$$
\left(K_{\text {skin }}+K_{\text {skull }}+K_{\text {fluid }}+K_{\text {brain }}\right) D=F
$$

When modifications are made for viscoplastic material, such as skin, brain tissue and fluid there is a need to change each matrix of rigidity. Consequently, each of these matrices has to be split into two, one that contains all distortion terms $\left(K_{d}\right)$ and the other that comprises the volumetric deformation $\left(K_{v}\right)$, then:

$$
K_{\text {tissue }}=(E v /((1+v)(1-2 v))) K_{V}+\left(E /(2(1-v)) K_{d}\right.
$$

Where:

$\mathrm{E}=$ bulk modulus of the material

$v=$ Poissons ratio

In the theory of plasticity, there is conservation of the body volume under stress, where needs to be set to 0,5. However, when modelling for FEM, to avoid producing an indefinitely large end value in the volumetric effect and to eliminate the distortion effect, the module of Poisson has to be inferior to 0,5. This is an important data element that needs to be introduced in the software. 
Horizontal slices at eye level are analysed. The FEM analysis are performed in two dimensions, with a layer thickness of $1 \mathrm{~mm}$. For the purposes of symmetry, saving time and RAM memory, the work was carried out in a semi-piece in most cases, except for the diffuse impact. The biological materials used in the model correspond to a child's.

The Input data are the external charge and Table 1]

Some of the input are described by: Antish [1], Sklar [8], Torres [1] and Heys [3].

Table 1. Input data of the head materials of a child

\begin{tabular}{|l|l|l|l|l|}
\hline & Mass Density & Modulus of Elasticity & Poisson's ratio & Shear Modulus \\
\hline Units & $\mathrm{Ns}^{2} / \mathrm{mm} / \mathrm{mm}^{3}$ & $\mathrm{~N} / \mathrm{mm}^{2}$ & & $\mathrm{~N} / \mathrm{mm}^{2}$ \\
\hline \hline Brain & 0.00105 & 1935 & 0.4 & 0.00083 \\
\hline Brain Liquid & 0.00102 & 2280 & 0.4 & 0.00002 \\
\hline Blood & 0.00104 & 2250 & 0.4 & 0.00002 \\
\hline Bone & 0.00112 & 7680 & 0.2 & 2800 \\
\hline Skin & 0.00101 & 2000 & 0.4 & 0.002 \\
\hline
\end{tabular}

\section{$3 \quad$ Results}

Three impact cases were analyzed:

1. A concentrate $90 \mathrm{~kg}$ blow on the left brain side. The results are the stresses and the strain. It is a punch of medium force, done by an adult.

2. A difussed $120 \mathrm{~kg}$ blow on the left brain side. The results are the nodal displacement. It is similar to a soccer ball impact, at short distance.

3. A frontal childs head collision at $5 \mathrm{~m} / \mathrm{s}$, like a cyclist accident. The results are the strain and nodal displacement.

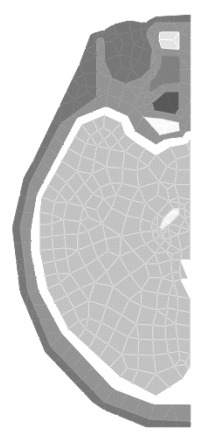

Fig. 1. FEM brain structure showing different materials: skin, bone of the cranium, brain's fluid and brain tissue. It is a horizontal slice at eye level. For the purposes of symmetry is a semi-piece. 

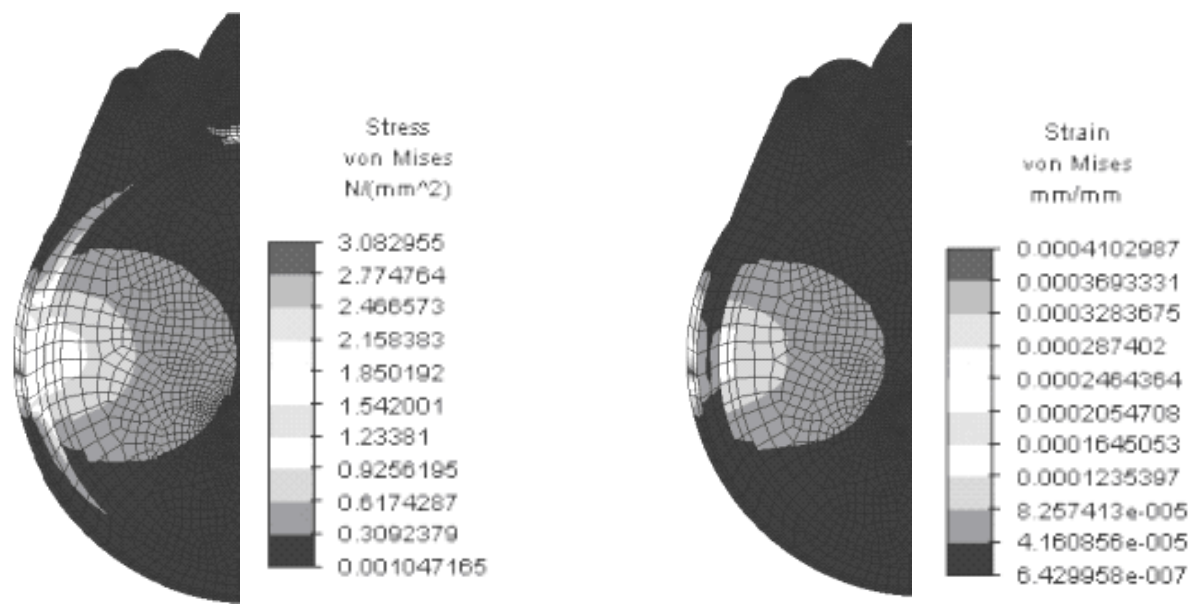

Fig. 2. FEM modeling showing stresses and strain produced by a concentrate $90 \mathrm{~kg}$ blow on the left brain side
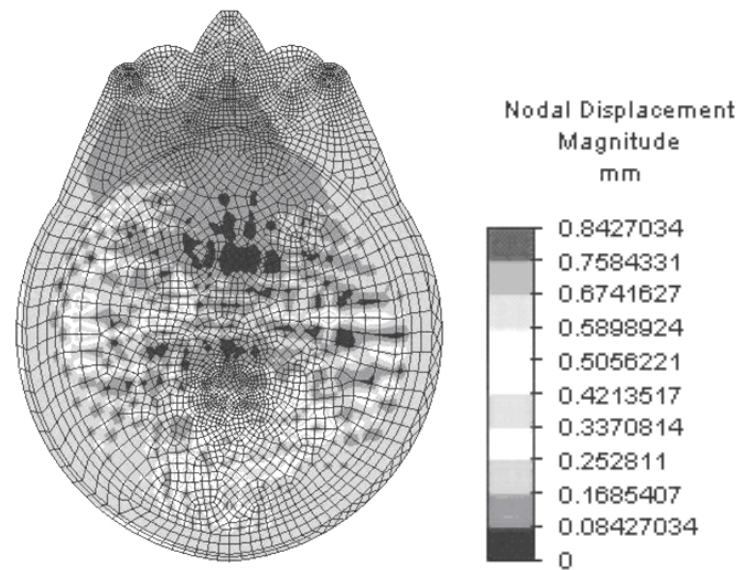

Fig. 3. FEM modeling. Nodal displacement. A head of a child under diffused $120 \mathrm{~kg}$ blow on the left brain side.

\section{Conclusions}

Figure 2 shows the analysis of distribution of tensions in the child's head caused by a non-traumatic impact focused on the bone. The impact is modelled on the left side of the brain. The pale colours indicate a greater concentration of stress just below the point of impact, but there are also some minor stresses towards the centre of the brain. The left hand side of figure 2 corresponds to the same case but in deformities. The prediction is that there would be local damage as well as internal damage to the brain. 

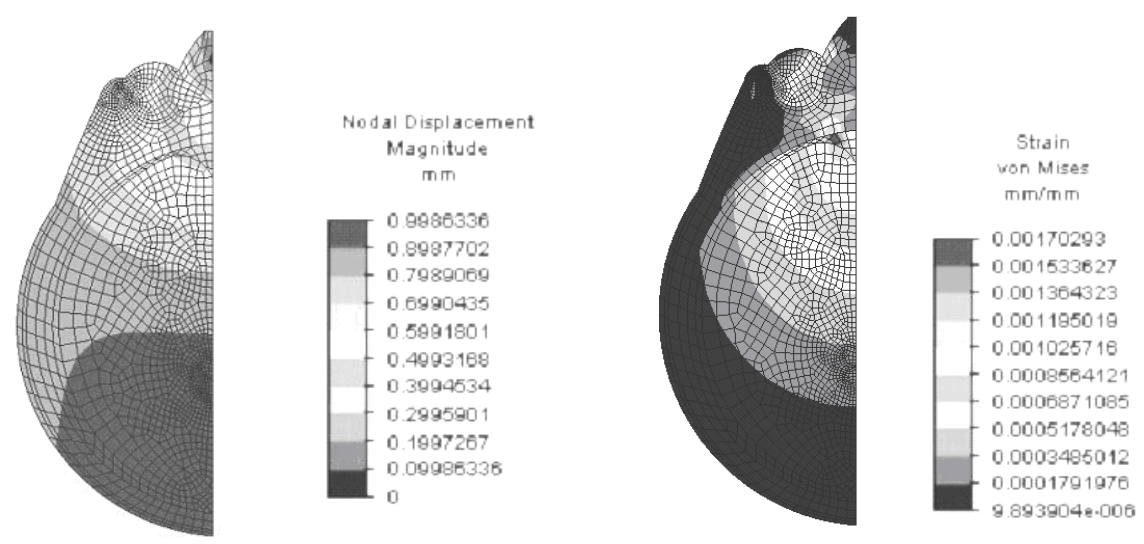

Fig. 4. Right side: FEM strain modeling. A frontal childs head collision at $5 \mathrm{~m} / \mathrm{s}$. The frontal lobe shows the biggest strain. Left side: Nodal displacement.

Figure 3 models the effect of a lateral impact distributed over a greater area. In this analysis of the nodal movements it is possible to observe movements of greater diffused magnitude which also extend towards the right side of the brain. This prediction would coincide with diffused traumas experienced by boxers, The Franklin Institute on Line, 9].

The right side of figure 4 shows the effect of an impact at $5 \mathrm{~m} / \mathrm{s}$, such as that happening to a cyclist. A flat impact on the child's forehead is modelled. The major deformations appearing on the frontal lobe would have a destructive result for the brain tissue. The damage appears beyond half of the brain, although diminishing in magnitude. The left hand side of figure 4 shows the nodal displacement of the brain. Due to the biggest displacement in the occipital lobe, it is possible damage by a rupture of the blood vessels and nerves of arachnoid net, between the skull and the brain. It is also possible a rebound against the back dome bone, getting a second internal impact.

The stress of rupture of a child's skull would be between 80 and $90 \mathrm{~N} / \mathrm{mm} 2$, but the arterioles break up at $0,126 \mathrm{~N} / \mathrm{mm} 2$ while the neurones do it at 0,133 $\mathrm{N} / \mathrm{mm} 2$. The bone would not fracture with these kind of impact, but the soft tissue would suffer lesions. These mathematical models can be used for designing better protective equipment and for demonstrating the brain damage in children caused by non-traumatic impacts on the skull.

\section{References}

1. Antish, P., et al.: Measurements of mechanical properties of bone material in vitro by ultrasound reflection: methodology and comparison with ultrasound transmission. Journal of Bone Miner Res. 3, 417-426 (1991)

2. Lee, I.: Interpretación Clínica de la Escala de Inteligencia de Wechsler. TEA Ediciones S.A., Madrid (1989) 
3. Heys, et al.: First-order system least-squares (FOSLS) for modelling blood flow. Medical Engineering and Phisics, Elsevier 28, 495-503 (2006)

4. Müsterberg, E.: Test Guestáltico Visomotor para Niños. Ed. Guadalupe. México (1999)

5. Ourselin, S.: Recalage d'images médicales par appariement de regions- Application á la construction d'atlas histologiques 3D., Tesis doctoral, Université de Nice (2002)

6. Pitiot, A.: Piecewise Affine Registration of Biological Images for Volume Reconstruction. Medical Image Analysis 3(3), 465-483 (2006)

7. Raine, A.: Prefrontal Damage in People with Antisocial Personality Disorder (Paper $)(2000)$

8. Sklar, F., Elashvili, I.: The pressure-volume function of brain elasticity. Physiological consideration and clinical applications. Journal of Neurosug 47(5), 670-679 (1977)

9. The Franklin Institute on Line, The human brain (2005), http://www.fi.edu.brain/index.htm\#

10. The Virtual Human Brain on line. Actual human brain dissection images (2005), http://www.vh.org/adult/provider/anatomy/BrainAnatomy/ BrainAnatomy.html

11. Torres, H., Zamorano, M.: SAR Simulation of Chiral Waves in a Head model. Rev. Facing 1(9), 3-19 (2001)

12. Yong, F., Tianzi, J.: Volumetric Segmentation of Brain Images Using Paralell Genetic Algorithms. IEEE Transactions on Medical Imaging 21(8), 904-909 (2002)

13. Zienkiewicz, O.: El Método de los Elementos Finitos, Reverté, España (1980) 